\title{
IL-8, a novel messenger to cross-link inflammation and tumor EMT via autocrine and paracrine pathways (Review)
}

\author{
XINXIN LONG ${ }^{1,3}$, YINGNAN YE ${ }^{2}$, LIJIE ZHANG $^{1,3}$, PENGPENG LIU $^{2}$, \\ WENWEN YU ${ }^{1}$, FENG WEI $^{1}$, XIUBAO REN $^{1,3}$ and JINPU YU ${ }^{1,2}$ \\ ${ }^{1}$ Department of Immunology, ${ }^{2}$ Biotherapy Center, Key Laboratory of Cancer Immunology and Biotherapy, \\ ${ }^{3}$ Cancer Molecular Diagnostic Center, Key Laboratory of Cancer Prevention and Therapy, National Clinical Research \\ Center of Cancer, Tianjin Medical University Cancer Institute and Hospital, Tianjin 300060, P.R. China
}

Received August 11, 2015; Accepted October 15, 2015

DOI: 10.3892/ijo.2015.3234

\begin{abstract}
The epithelial-mesenchymal transition (EMT) is a process through which epithelial cells trans-differentiate and acquire an aggressive mesenchymal phenotype. In tumor cells, EMT is a vital step of tumor progression and metastasis. Amid the increasing interest in tumor EMT, only a few studies focused on the soluble mediators secreted by tumor cells passing through this phenotypic switch. In this review, we focus on the essential role of interleukin-8 (IL-8) signaling for the acquisition and maintenance of tumor EMT via direct and indirect mechanisms. Besides the autocrine loop between IL-8 and tumor cells that have gone through EMT, IL-8 could potentiate adjacent epithelial tumor cells into a mesenchymal phenotype via a paracrine mode. Moreover, understanding the role of IL-8 in EMT will provide insight into the pathogenesis of tumor progression and may facilitate the development of an effective strategy for the prevention and treatment of metastatic cancer.
\end{abstract}

\section{Contents \\ 1. Introduction \\ 2. EMT of tumor \\ 3. IL-8}

Correspondence to: Dr Jinpu Yu, Department of Immunology, Key Laboratory of Cancer Immunology and Biotherapy, National Clinical Research Center of Cancer, Tianjin Medical University Cancer Institute and Hospital, Huanhuxi Road, Hexi, Tianjin 300060, P.R. China

E-mail: yujinpu@tjmuch.com

Abbreviations: EMT, epithelial-mesenchymal transition; CSC, cancer stem cell; TAM, tumor-associated macrophage; GSK3 $\beta$, glycogen synthase kinase $3 \beta$; ECM, extracellular matrix; TGF- $\beta$, transforming growth factor- $\beta$; TNF- $\alpha$, tumor necrosis factor $\alpha$; MMP, matrix metalloproteinase; CCL18, chemokine ligand 18

Key words: IL-8, epithelial-mesenchymal transition, autocrine, paracrine, signal pathways
4. The role of IL-8 in EMT

5. IL-8 as target for cancer therapy

6. Conclusion

\section{Introduction}

Tumor microenvironment, a vastly complicated network composed of various cell populations, soluble factors, signaling molecules and extracellular matrix components, orchestrates the behavior of tumor progression (1). Amid the growing interest in elucidating individual players in the tumor microenvironment, IL-8 appears markedly important and has been presented as one of the prominent promoters of tumor progression. IL-8 is involved in cancer related inflammation. A typical example is that, Epstein-Barr virus (EBV)-associated, undifferentiated type of nasopharyngeal carcinoma (NPC) which is characterized by several inflammation-like features. The inflammation-like microenvironment is crucial for the development of NPC progression. Notably, EBV infection as a critical factor for cancer progression can induce IL-8 secretion. EBV lytic transactivator Zta, which exerting its effect through bingding to Zta-responsive elements, resides in the IL-8 promoter (2).

A pivotal step to establish the progression of a tumor is the obtainment of aggressive characteristics by carcinoma cells. A primary process triggering tumor invasion is EMT through which cancer epithelial cells lose their epithelial properties and trans-differentiate to a migratory mesenchymal phenotype (3). EMT has recently been recognized as a key player contributing to tumor progression and the mechanisms regulating this process have been linked to metastasis and cancer stem cell-like cell formation $(4,5)$. Various signaling events have been proposed to facilitate EMT in a variety of human tumors. However, initiating EMT in a tumor is mainly dependent on multiple soluble mediators in the surrounding microenvironment (6).

In this review, we aim at elucidating the complex interactions of IL-8 induction of EMT through direct and indirect mechanisms. We introduce current research on the cytokines, pro-inflammatory mediators and enzymes secreted by neutrophils and TAMs and the mechanism of their induction of EMT. 
Additionally, we address the potential therapeutic implications of IL-8 cancer treatment.

\section{EMT of tumor}

EMT originally takes place during the process of embryogenesis, but it also occurs in adult tissues going through wound healing and remodeling (7). Moreover, in some certain pathological process it is associated with fibrosis and tumor progression. During the EMT process, epithelial cancer cells evolve to a mesenchymal phenotype, by losing their epithelial characteristics and acquiring a fibroblastoid-like morphology especially at the invasive front. Cells undergoing EMT reduce cell polarity and adhesion, exhibit decreased expression of epithelial surface molecules such as E-cadherin and cytokeratins. In parallel, epithelial tumor cells acquire enhanced presentation of mesenchymal proteins such as vimentin and fibronectin as well as increased cell motility, invasiveness and metastasis (8).

Recent studies have focused on EMT in the tumor biology context, since acquisition of mesenchymal features is linked to an improved invasive capacity, that is, could promote tumor infiltrating growth and metastasis (9). Multiple studies have shown that the involvement of EMT is related to tumor progression in different tumor types (10-12). For instance, in adenoid cystic carcinoma which is characteristed by local infiltration and distant metastasis, EMT is considered to promote greatly the high rate of metastasis (13). Consistently, downregulation of epithelial marker E-cadherin and increased expression of the mesenchymal markers $\mathrm{N}$-cadherin and vimentin have noted to positively correlate with the aggressiveness and metastasis of breast cancer (14).

Additionally, several reports have shown that cancer cells undergoing EMT present properties of cancer stem cells (CSC) (5), including chemo- and radio-resistance and the ability to self-renewal. Fan demonstrated that hepatocellular carcinoma cells undergoing EMT acquire enhanced CSC-like traits when co-cultured with TAM. Furthermore, depletion of TGF- $\beta 1$ blocked acquisition of the CSC-like properties by inhibition of TGF- $\beta 1$-induced EMT (15). Increasing number of studies have identified distinct signaling pathways regulating this step $(16,17)$.

\section{IL-8}

IL-8 (alternatively known as CXCL8), a prototype of the cysteine-X-cysteine (CXC) chemokines, was originally discovered as a leukocyte chemoattractant (18) and subsequently found to play multiple roles in cancer development (3). Human genes for IL- 8 are located on chromosome 4 between $4 \mathrm{q} 13$ and 4q21 (19). IL-8 is mainly secreted from leukocytes and endothelial cells under special conditions such as exposure to IL-1 or TNF- $\alpha$. Additionally, fibroblasts and malignant tumor cells can also secrete IL-8 as a result of various environmental stress including hypoxia, and chemotherapy agents (20). Since existing in monomer or dimer forms, IL-8 activates and regulates its two cell surface receptors respectively (21).

IL-8 exerts its effect by binding to the IL-8Rs, which are two heterotrimeric G protein-coupled receptors, CXCR1 and CXCR2. The two receptors are primarily presented in neutro- phils, monocytes as well as endothelial cells. However, they are also found on the surface of tumor cells and tumor-associated stromal cells (22). The two receptors show different binding specificities as a result of differences in their $\mathrm{N}$-terminal domains (23). CXCR1 binds IL-6 and IL-8, while CXCR2 has high binding affinity for IL-1, 2, 3, 5, 6, 7 and 8 (24).

IL-8 has demonstrated to induce angiogenesis (25) and promote the progression of many human cancers including prostate cancer (26), non-small cell lung carcinoma (27), melanoma (28), and ovarian cancer (29). Moreover, studies have shown that IL-8 has prognostic value in many malignant tumors $(30,31)$. Aberrantly elevated serum IL-8 level can even precede diagnosis of lung cancer by several years (32). Tumorderived IL- 8 induces proliferation and migration of tumor cell via its autocrine activity. Simultaneously, IL-8 promots the angiogenic response in endothelial cells and the recruitment of neutrophils to the tumor site via its paracrine activity (33).

It has been reported that IL- 8 is regulated by microRNA network at post-transcription level (34) and significant correlation between microRNAs and IL-8 is identified in a variety of studies. miR-302c was found to inhibit IL-8 expression and restrain tumor invasion and metastasis. In parallel, IL-8 signaling also exerts a feedback effect on modulating miR-302c and IL-8 expression (35). Qu et al suggested that IL-8 was a direct target of miR-203 and miR-23a. Reduced expression of the two miRNAs promoted nasopharyngeal carcinoma radioresistance through IL-8/AKT signaling and IL-8/Stat3 pathway respectively $(36,37)$. Additionally, hsamiR-200c-3p directly reduced IL-8 expression in inflamed colon of patients with ulcerative colitis (38). Moreover, IL-8 can be suppressed by diverse miRNAs such as miR-K9, miR-K5, miR-17, miR-484, and miR-148a, through indirect manner $(34,39-41)$. On the other hand, microRNA network has been found to be very important in tumor initiation and progression. Several anti-metastatic miRNAs have been identified in a number of cancers, such as miR-335, miR-126, and let-7 family. In addition to anti-metastatic miRNAs, a number of miRNAs are pro-metastatic such as miR-21, miR-373 and miR-520c $(42,43)$.

\section{The role of IL-8 in EMT}

Tumor cells passing through EMT have been indentified to secrete more chemokine IL- 8 as well as to enhance the expression of its receptors. Tumor-derived IL-8 exerts its effect through an autocrine loop to maintain the mesenchymal traits of tumor cells. Furthermore, IL-8 recruits neutrophils and TAMs to the tumor site via a paracrine fashion. In this review, we highlight the cytokines, pro-inflammatory mediators and enzymes secreted by neutrophils and TAMs as well as the mechanism of their induction of EMT.

i) Autocrine IL-8 loop maintain tumor EMT. It is demonstrated that, once through EMT, tumor cells maintain their mesenchymal state by ongoing autocrine signaling loops (44). IL-8 stimulates tumor EMT by activation of various signaling pathways that finally affect the EMT-related transcription factors (Fig. 1). The transcription factors Slug, Snail, and Twist are known to bind to the E-box regulatory regions to repress the expression of E-cadherin (7). Recently, a T-box transcrip- 


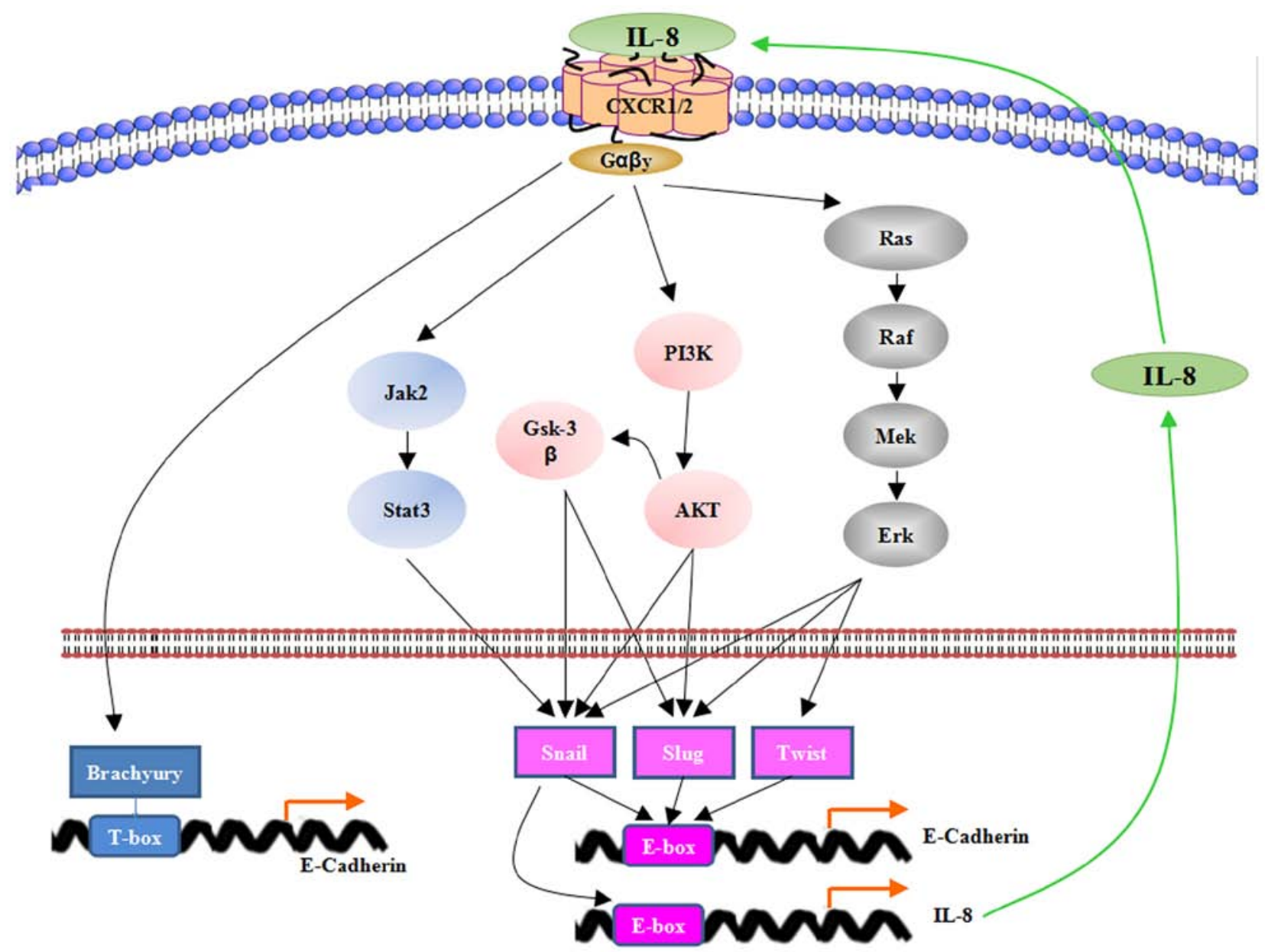

Figure 1. Autocrine IL-8 loop maintain tumor EMT. Tumor-derived IL-8 function in a positive autocrine loop to maintain the mesenchymal traits of tumor cells mainly through AKT, MAPK/ERK and JAK2/STAT3 signaling pathways. Besides, IL-8 can induce the overexpression of T-box transcription factor Brachyury leading to reduced expression of E-cadherin.

tion factor brachyury was identified as a novel trigger of tumor EMT (45). Therefore, the mesenchymal transition occurs. In return, the induction of EMT via Snail upregulation is noted to induce IL-8 secretion. Since Snail could bind to E3/E4 boxes residing in the IL-8 promoter, it directly regulates the expression of IL-8 (46).

IL-8 has been shown to activate AKT signaling in prostate cancer, nasopharyngeal carcinoma (NPC) and thyroid cancer (TC) cell lines (47-49). The serine/threonine kinase AKT, a downstream target of PI3K, phosphorylated glycogen synthase kinase $3 \beta$ (GSK3 $\beta$ ) which induced the phosphorylation and translocation of Snail and Slug $(50,51)$. Thereby, inhibiting GSK-3 $\beta$ activity, AKT activates Snail and Slug indirectly, leading to EMT. In NPC S18 cells, the elevated level of phosphorylated AKT could be suppressed by knocking down IL-8 expression using short-hairpin RNA. Moreover, IL-8promoted EMT could be inhibited by knocking down AKT expression or applying the PI3K inhibitor LY294002. Besides, suppression of AKT has been shown to revert EMT and stemness responses of TC cells.

MAPK/ERK signaling is accepted as one of the most important regulators in EMT. Via activating small $\mathrm{G}$ proteins, IL-8 promotes activation of the MAPK signaling which is characterized by Raf/MEK/ERK cascade (52). ERK trans- locates to the nucleus and upregulates the activity of several EMT-related transcription factors such as Snail, Slug and Twist. Therefore, the expression of E-cadherin is suppressed $(53,54)$. In addition, IL-8 has been found to induce EMT and promote hepatocellular carcinoma (HCC) cell migration and invasion through JAK2/STAT3/Snail signaling pathway (55).

Additionally to the E-box transcription factors, Brachyury, the T-box transcription factor, has been discovered to promote tumor EMT and cancer cell metastasis in multiple types of human cancer (45). In breast cancer cells, IL-8 induces the overexpression of Brachyury and a mesenchymal-like phenotype. Furthermore, Brachyury displays increased expression of IL- 8 and CXCR1/2, which amplified the effect of IL-8 on tumor EMT (56).

ii) Paracrine factors promote tumor EMT. Besides the autocrine loop between IL-8 and tumor cells that have gone through EMT, IL-8 could potentiate adjacent epithelial tumor cells into a mesenchymal phenotype via a paracrine mode (Fig. 2). Tumor cells undergoing EMT exhibit an elevated level of IL-8 as well as CXCR1/2, which amplified the effect of IL-8 on tumor EMT. Besides the effects on tumor cells, IL-8 is identified as an important regulator of neutrophils and TAMs recruited into the tumor microenvironment. 

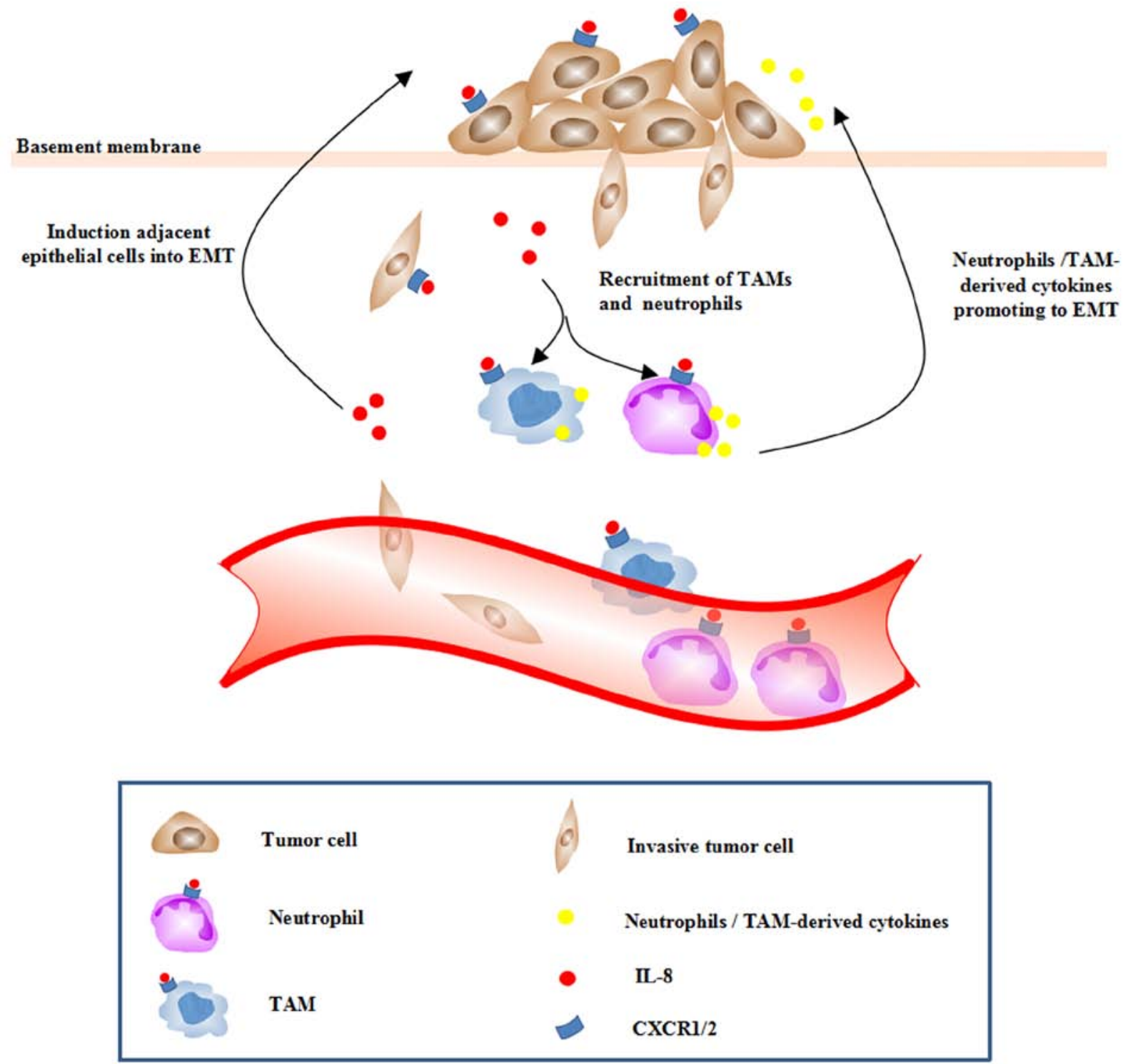

Figure 2. Paracrine IL-8 promotes tumor EMT, IL-8 could potentiate adjacent epithelial tumor cells into EMT by a paracrine mode. IL-8 activates endothelial cells in the tumor vasculature to promote angiogenesis and induces a chemotactic infiltration of neutrophils and TAMs into the tumor site. Neutrophils and TAMs secrete additional growth factors, cytokines, chemokines, enzymes further promoting EMT in the tumor microenvironment.

Macrophages infiltrated in the tumor sites have been shown to induce EMT of HCC cells. TAMs can secrete a vast diversity of cytokines, chemokines and proteases that may influence tumor cells in various ways. Mast cells induced EMT and stem-like traits of TC cells (49). The enhanced intratumoral IL-8 expression could also lead to enhanced recruitment of neutrophils and TAMs, which, in turn, have been found to secrete various cytokines, chemokines, enzymes promoting EMT. Various cytokines (TGF- $\beta 1$, TNF- $\alpha$, IL- 4 , IL- 6 and IL-10) secreted by activated macrophages in the cholangiocarcinoma context were shown to induce EMT via elevating the expression of EMT-related genes (57).

Cytokines and chemokines function mainly by binding to certain transmembrane receptors of tumor cells, which are members of a large family of $\mathrm{G}$ protein-coupled receptors. In parallel, some enzymes act on the extracellular matrix (ECM), breakdown connective tissue, inhibit E-cadherin synthesis and promote the mesenchymal phenotype in tumor cells.
Growth factors. As one of the most important members of the transforming growth factor family, transforming growth factor- $\beta$ (TGF- $\beta$ ) is a potential inducer of EMT in cancer cells $(58,59)$. TGF- $\beta$ mediates EMT via two specific pathways, a Smad-dependent pathway and a Smad-independent pathway (60). After binding to its receptor, TGF- $\beta$ phosphorylates Smad2 and Smad3, which collaborate with Smad4, and then translocate into the nucleus to regulate the transcription of EMT-associated genes, like Snail (61). Bonde et al found that TAMs induced intratumoral epithelial cell EMT via TGF- $\beta /$ Smad signaling. Data presented in his study identified that macrophage-derived TGF- $\beta$ led to decreased expression of the epithelial adhesion, increased expression of mesenchymal markers and an aggressive phenotype (62). Additionally, cancer-associated fibroblasts could also promote EMT of breast cancer cells through paracrine TGF- $\beta 1$ (63).Collective studies have shown TGF- $\beta 1$ induced EMT mainly through Smad, MAPK, PI3K/AKT and ERK pathway. 
Several studies now indicate that EGF activation can break cell adhesion, enhance cell motility and promote tumor EMT $(64,65)$. In EGF-treated cholangiocarcinoma cells, EMT-transcription factors as well as mesenchymal markers were induced. In addition, the EGF-mediated EMT can be suppressed by gefitinib, the inhibitor of EGFR (66).

Cytokines and chemokines. IL-6 has been suggested to induce EMT in breast, colorectal, prostate and lung cancer cells (67-70) via aberrant activation of JAK/STAT3 signaling. Additionally, IL- 6 boosted the expression of Snail induced by TGF- $\beta /$ Smad pathway, contributing greatly to EMT $(61,71)$.

Similarly to IL-6, IL-1 $\beta$ contributes to EMT via different pathways. IL-1 $\beta$ enhanced binding of Zeb1 to the E-box to silence E-cadherin expression (72). IL-1 $\beta$ has also been reported to promote the expression of E-cadherin by upregulaing Snail (73). In addition, cooperated with TGF $\beta-3$, IL-1 $\beta$ activated matrix metalloproteinase (MMP)-1, MMP-3, and MMP-10 gene expression in A549 lung adenocarcinoma cells through MAPK-dependent pathways, and both cytokines stimulated EMT and invasion (74).

Tumor necrosis factor $\alpha$ (TNF- $\alpha$ ), which is primarily derived from by macrophages, is one of the critical pro-inflammatory cytokines involved in the tumor microenvironment (75). Several studies suggest that TNF- $\alpha$ induces EMT via NF- $\mathrm{BB}$ or AKT/GSK signaling through regulating the expression of Twist and Snail in breast, renal, colon and hypopharyngeal cancer $(4,76)$. Collectively, the evidence indicates that TNF- $\alpha$ may affect the key processes of tumor EMT.

TAM with M2 phenotype could produce a chemokine called chemokine (C-C motif) ligand 18 (CCL18) (77) which exerts its activity mainly by binding to the transmembrane receptor-PYK2 N-terminal domain interacting receptor 1 (Nir1). Nir1 is present in human breast cancer cells (78) and it could induce EMT by stabilising Snail via the PI3K/AKT/ GSK3 $\beta$ signaling pathway through binding to CCL18 in vitro and in vivo (79).

Enzymes. Studies have shown that neutrophil-derived elastase could degradate E-cadherin leading to dyshesion of the pancreatic ductal adenocarcinoma and HCC cells. Furthermore, the EMT transcription factor Twist was upregulated,Zeb1 appeared in the nucleus, $\beta$-catenin translocated into the nucleus, and keratins were downregulated (80). In addition, the MMPs that exist in the ECM are associated with various EMT processes. The MMPs have the ability to degrade the functional components of the ECM and contribute to tumor cell migration. Therefore, the mesenchymal transition occurs and each EMT case involves a subset of specific MMPs.

Overexpression of MMP-9 in a prostate cancer model confirmed the association of MMP-9 with tumor invasiveness (81). It has also been found in a gastric carcinoma model that IL-8 upregulates MMP-9 expression and consequently increased neoangiogenesis (82). Besides, TNF- $\alpha$ induces the expression of invasion mediators MMP-7, MMP-9, and the intracellular adhesion molecule-1.

Taken together, various growth factors, cytokines, chemokines as well as enzymes secreted by TAMs and neutrophils can facilitate EMT of tumor cells.

\section{IL-8 as target for cancer therapy}

As IL-8 is associated with EMT and tumor progression, it is of interest to speculate that therapy targeting IL- 8 could improve tumor outcome. Blockade of the IL- 8 and its receptors seems a promising therapeutic approach which could reverse the metastatic phenotype of tumor cells undergoing EMT by disturbing the autocrine positive loop between IL- 8 and tumor cells. Additionally, it could also reduce the paracrine signals that IL-8 exerted on other non-metastatic tumor cells by lessening recruitment of neutrophils and TAMs. CXCR2 is upregulated in some types of tumors (83-85) and pharmacological inhibition of CXCR1 and CXCR2 represses neutrophil recruitment into A547 lung tumor sites resulting in slower tumor growth (86). Small-molecule antagonists for CXCR2 and CXCR1 have been proposed to inhibit IL-8 functions.

Studies show that CXCR1 blockade by either a CXCR1 specific blocking antibody or repertaxin, a small-molecule CXCR1 inhibitor, selectively depleted human breast cancer stem cells (87). In addition, selectively targeting CXCR2/ CXCR1 with orally active small-molecule inhibitors is an effective therapeutic approach for repressing melanoma growth and angiogenesis (88). CXCR2/CXCR1 antagonists may be a useful therapeutic agent in the treatment of many other cancers, such as lung carcinomas.

Small-molecule antagonists for CXCR2 and CXCR1 may represent a promising target for cancer therapy. A better understanding of the function of IL- 8 and further knowledge on the interaction between IL- 8 and tumor microenvironment may open the way to innovative therapeutic strategies for cancer patients.

\section{Conclusion}

EMT plays a central role in tumor invasion and metastasis and may be induced by local inflammation. In this review, we focused on IL-8, because it is a major component of the infiltrates present in the tumor microenvironment and plays a vital role in the tumor progression and metastasis. We highlight the cross-link between inflammation and EMT-related tumor development. IL-8 induction of EMT, despite being sophisticated and requiring solid experimental investment, opens new horizons for an efficient tumor therapy.

\section{Acknowledgements}

This study was supported by National Basic Research Program of China (973 program) no. 2012CB9333004, National Natural Science Foundation of China (81272360) and National Natural Science Foundation of China (81472473).

\section{References}

1. Catalano V, Turdo A, Di Franco S, Dieli F, Todaro M and Stassi G: Tumor and its microenvironment: A synergistic interplay. Semin Cancer Biol 23B: 522-532, 2013.

2. Hsu M, Wu SY, Chang SS, Su IJ, Tsai CH, Lai SJ, Shiau AL, Takada $\mathrm{K}$ and Chang Y: Epstein-Barr virus lytic transactivator Zta enhances chemotactic activity through induction of interleukin-8 in nasopharyngeal carcinoma cells. J Virol 82: 3679-3688, 2008. 
3. Thiery JP, Acloque H, Huang RY and Nieto MA: Epithelialmesenchymal transitions in development and disease. Cell 139: 871-890, 2009.

4. Wu Y, Deng J, Rychahou PG, Qiu S, Evers BM and Zhou BP: Stabilization of snail by NF-kappaB is required for inflammationinduced cell migration and invasion. Cancer Cell 15: 416-428, 2009.

5. Mani SA, Guo W, Liao MJ, Eaton EN, Ayyanan A, Zhou AY, Brooks M, Reinhard F, Zhang CC, Shipitsin M, et al: The epithelial-mesenchymal transition generates cells with properties of stem cells. Cell 133: 704-715, 2008

6. Sabbah M, Emami S, Redeuilh G, Julien S, Prévost G, Zimber A, Ouelaa R, Bracke M, De Wever O and Gespach C: Molecular signature and therapeutic perspective of the epithelial-to-mesenchymal transitions in epithelial cancers. Drug Resist Updat 11: 123-151, 2008.

7. Kalluri R and Weinberg RA: The basics of epithelial-mesenchymal transition. J Clin Invest 119: 1420-1428, 2009.

8. Micalizzi DS, Farabaugh SM and Ford HL: Epithelialmesenchymal transition in cancer: Parallels between norma development and tumor progression. J Mammary Gland Biol Neoplasia 15: 117-134, 2010.

9. Thiery JP: Epithelial-mesenchymal transitions in tumour progression. Nat Rev Cancer 2: 442-454, 2002.

10. Guarino M, Rubino B and Ballabio G: The role of epithelialmesenchymal transition in cancer pathology. Pathology 39: 305-318, 2007.

11. Gravdal K, Halvorsen OJ, Haukaas SA and Akslen LA: A switch from $\mathrm{E}$-cadherin to $\mathrm{N}$-cadherin expression indicates epithelial to mesenchymal transition and is of strong and independent importance for the progress of prostate cancer. Clin Cancer Res 13: 7003-7011, 2007

12. Sawada K, Mitra AK, Radjabi AR, Bhaskar V, Kistner EO, Tretiakova M, Jagadeeswaran S, Montag A, Becker A, Kenny HA, et al: Loss of E-cadherin promotes ovarian cancer metastasis via alpha 5-integrin, which is a therapeutic target. Cancer Res 68 2329-2339, 2008 .

13. Zhao ZL, Ma SR, Wang WM, Huang CF, Yu GT, Wu TF, $\mathrm{Bu}$ LL, Wang YF, Zhao YF, Zhang WF, et al: Notch signaling induces epithelial-mesenchymal transition to promote invasion and metastasis in adenoid cystic carcinoma. Am J Transl Res 7: $162-174,2015$

14. Sarrió D, Rodriguez-Pinilla SM, Hardisson D, Cano A, MorenoBueno $G$ and Palacios J: Epithelial-mesenchymal transition in breast cancer relates to the basal-like phenotype. Cancer Res 68 : 989-997, 2008

15. Fan QM, Jing YY, Yu GF, Kou XR, Ye F, Gao L, Li R, Zhao QD, Yang Y, Lu ZH, et al: Tumor-associated macrophages promote cancer stem cell-like properties via transforming growth factor-betal-induced epithelial-mesenchymal transition in hepatocellular carcinoma. Cancer Lett 352: 160-168, 2014.

16. Javle MM, Gibbs JF, Iwata KK, Pak Y, Rutledge P, Yu J, Black JD, Tan D and Khoury T: Epithelial-mesenchymal transition (EMT) and activated extracellular signal-regulated kinase (p-Erk) in surgically resected pancreatic cancer. Ann Surg Oncol 14: 3527-3533, 2007

17. Horiguchi K, Sakamoto K, Koinuma D, Semba K, Inoue A, Inoue S, Fujii H, Yamaguchi A, Miyazawa K, Miyazono K, et al: TGF- $\beta$ drives epithelial-mesenchymal transition through $\delta E F 1-$ mediated downregulation of ESRP. Oncogene 31: 3190-3201, 2012.

18. Matsushima K, Baldwin ET and Mukaida N: Interleukin-8 and MCAF: Novel leukocyte recruitment and activating cytokines. Chem Immunol 51: 236-265, 1992.

19. Brat DJ, Bellail AC and Van Meir EG: The role of interleukin- 8 and its receptors in gliomagenesis and tumoral angiogenesis. Neuro-oncol 7: 122-133, 2005.

20. Xie K: Interleukin-8 and human cancer biology. Cytokine Growth Factor Rev 12: 375-391, 2001.

21. Nasser MW, Raghuwanshi SK, Grant DJ, Jala VR, Rajarathnam K and Richardson RM: Differential activation and regulation of CXCR1 and CXCR2 by CXCL8 monomer and dimer. J Immunol 183: 3425-3432, 2009.

22. Stillie R, Farooq SM, Gordon JR and Stadnyk AW: The functional significance behind expressing two IL-8 receptor types on PMN. J Leukoc Biol 86: 529-543, 2009.

23. Murphy PM: The molecular biology of leukocyte chemoattractant receptors. Annu Rev Immunol 12: 593-633, 1994

24. Balkwill F: Cancer and the chemokine network. Nat Rev Cancer 4: $540-550,2004$.
25. Végran F, Boidot $\mathrm{R}$, Michiels $\mathrm{C}$, Sonveaux $\mathrm{P}$ and Feron $\mathrm{O}$ Lactate influx through the endothelial cell monocarboxylate transporter MCT1 supports an NF- $\kappa \mathrm{B} / \mathrm{IL}-8$ pathway that drives tumor angiogenesis. Cancer Res 71: 2550-2560, 2011.

26. Araki S, Omori Y, Lyn D, Singh RK, Meinbach DM, Sandman Y, Lokeshwar VB and Lokeshwar BL: Interleukin-8 is a molecular determinant of androgen independence and progression in prostate cancer. Cancer Res 67: 6854-6862, 2007.

27. Millar HJ, Nemeth JA, McCabe FL, Pikounis B and Wickstrom E Circulating human interleukin- 8 as an indicator of cancer progression in a nude rat orthotopic human non-small cell lung carcinoma model. Cancer Epidemiol Biomarkers Prev 17: 2180-2187, 2008.

28. Rofstad EK and Halsør EF: Vascular endothelial growth factor, interleukin 8, platelet-derived endothelial cell growth factor, and basic fibroblast growth factor promote angiogenesis and metastasis in human melanoma xenografts. Cancer Res 60: 4932-4938, 2000.

29. Shahzad MM, Arevalo JM, Armaiz-Pena GN, Lu C, Stone RL, Moreno-Smith M, Nishimura M, Lee JW, Jennings NB, Bottsford-Miller J, et al: Stress effects on FosB- and interleukin-8 (IL8)-driven ovarian cancer growth and metastasis. J Biol Chem 285: 35462-35470, 2010

30. Ahmed OI, Adel AM, Diab DR and Gobran NS: Prognostic value of serum level of interleukin-6 and interleukin-8 in metastatic breast cancer patients. Egypt J Immunol 13: 61-68, 2006.

31. Shahzad A, Knapp M, Lang I and Köhler G: Interleukin 8 (IL-8) - a universal biomarker? Int Arch Med 3: 11, 2010.

32. Pine SR, Mechanic LE, Enewold L, Chaturvedi AK, Katki HA, Zheng YL, Bowman ED, Engels EA, Caporaso NE and Harris CC: Increased levels of circulating interleukin 6, interleukin 8, C-reactive protein, and risk of lung cancer. J Natl Cancer Inst 103: 1112-1122, 2011.

33. Gabellini C, Trisciuoglio D, Desideri M, Candiloro A, Ragazzoni Y, Orlandi A, Zupi G and Del Bufalo D: Functional activity of CXCL8 receptors, CXCR1 and CXCR2, on human malignant melanoma progression. Eur J Cancer 45: 2618-2627, 2009.

34. Cullen BR: MicroRNAs as mediators of viral evasion of the immune system. Nat Immunol 14: 205-210, 2013

35. Chen L, Min L, Wang X, Zhao J, Chen H, Qin J, Chen W, Shen Z, Tang Z, Gan Q, et al: Loss of RACK1 Promotes Metastasis of Gastric Cancer by Inducing a miR-302c/IL8 Signaling Loop. Cancer Res 75: 3832-3841, 2015.

36. Qu JQ, Yi HM, Ye X, Zhu JF, Yi H, Li LN, Xiao T, Yuan L, Li JY, Wang YY, et al: MiRNA-203 reduces nasopharyngeal carcinoma radioresistance by targeting IL-8/AKT signaling. Mol Cancer Ther: Aug 24, 2015 (Epub ahead of print]).

37. Qu JQ, Yi HM, Ye X, Li LN, Zhu JF, Xiao T, Yuan L, Li JY, Wang YY, Feng J, et al: MiR-23a sensitizes nasopharyngeal carcinoma to irradiation by targeting IL-8/Stat 3 pathway. Oncotarget 6: 28341-28356, 2015.

38. Van der Goten J, Vanhove W, Lemaire K, Van Lommel L, Machiels K, Wollants WJ, De Preter V, De Hertogh G, Ferrante M, Van Assche G, et al: Integrated miRNA and mRNA expression profiling in inflamed colon of patients with ulcerative colitis. PLoS One 9: e116117, 2014.

39. Oglesby IK, Vencken SF, Agrawal R, Gaughan K, Molloy K, Higgins G, McNally P, McElvaney NG, Mall MA and Greene CM: miR-17 overexpression in cystic fibrosis airway epithelial cells decreases interleukin-8 production. Eur Respir J ERJ-01634-2014, 2015.

40. Mei Q, Xue G, Li X, Wu Z, Li X, Yan H, Guo M, Sun S and Han W: Methylation-induced loss of miR-484 in microsatelliteunstable colorectal cancer promotes both viability and IL-8 production via CD137L. J Pathol 236: 165-174, 2015.

41. Li L, Liu Y, Guo Y, Liu B, Zhao Y, Li P, Song F, Zheng H, Yu J, Song T, et al: Regulatory miR-148a-ACVR1/BMP circuit defines a cancer stem cell-like aggressive subtype of hepatocellular carcinoma. Hepatology 61: 574-584, 2015.

42. Ding XM: MicroRNAs: Regulators of cancer metastasis and epithelial-mesenchymal transition (EMT). Chin J Cancer 33 140-147, 2014.

43. Sun Y, Guo F, Bagnoli M, Xue FX, Sun BC, Shmulevich I, Mezzanzanica D, Chen KX, Sood AK, Yang D, et al: Key nodes of a microRNA network associated with the integrated mesenchymal subtype of high-grade serous ovarian cancer. Chin J Cancer 34: 28-40, 2015.

44. Scheel C, Eaton EN, Li SH, Chaffer CL, Reinhardt F, Kah KJ, Bell G, Guo W, Rubin J, Richardson AL, et al: Paracrine and autocrine signals induce and maintain mesenchymal and stem cell states in the breast. Cell 145: 926-940, 2011 
45. Fernando RI, Litzinger M, Trono P, Hamilton DH, Schlom J and Palena C: The T-box transcription factor Brachyury promotes epithelial-mesenchymal transition in human tumor cells. J Clin Invest 120: 533-544, 2010.

46. Hwang WL, Yang MH and Tsai ML, Lan HY, Su SH, Chang SC, Teng HW, Yang SH, Lan YT, Chiou SH, et al: SNAIL regulates interleukin-8 expression, stem cell-like activity, and tumorigenicity of human colorectal carcinoma cells. Gastroenterology 141: 279-291, 291, 2011.

47. MacManus CF, Pettigrew J, Seaton A, Wilson C, Maxwell PJ, Berlingeri S, Purcell C, McGurk M, Johnston PG and Waugh DJ: Interleukin-8 signaling promotes translational regulation of cyclin D in androgen-independent prostate cancer cells. Mol Cancer Res 5: 737-748, 2007.

48. Li XJ, Peng LX, Shao JY, Lu WH, Zhang JX, Chen S, Chen ZY, Xiang YQ, Bao YN, Zheng FJ, et al: As an independent unfavorable prognostic factor, IL-8 promotes metastasis of nasopharyngeal carcinoma through induction of epithelialmesenchymal transition and activation of AKT signaling. Carcinogenesis 33: 1302-1309, 2012.

49. Visciano C, Liotti F, Prevete N, Cali' G, Franco R, Collina F, de Paulis A, Marone G, Santoro M and Melillo RM: Mast cells induce epithelial-to-mesenchymal transition and stem cell features in human thyroid cancer cells through an IL-8-Akt-Slug pathway. Oncogene 34: 5175-5186, 2015.

50. Mannoury la Cour C, Salles MJ, Pasteau V and Millan MJ Signaling pathways leading to phosphorylation of Akt and GSK-3 $\beta$ by activation of cloned human and rat cerebral $\mathrm{D}_{2}$ and $\mathrm{D}_{3}$ receptors. Mol Pharmacol 79: 91-105, 2011.

51. Kim JY, Kim YM, Yang CH, Cho SK, Lee JW and Cho M: Functional regulation of Slug/Snail2 is dependent on GSK-3 $\beta$ mediated phosphorylation. FEBS J 279: 2929-2939, 2012.

52. Knall C, Young S, Nick JA, Buhl AM, Worthen GS and Johnson GL: Interleukin-8 regulation of the Ras/Raf/mitogenactivated protein kinase pathway in human neutrophils. J Biol Chem 271: 2832-2838, 1996.

53. Nagarajan D, Melo T, Deng Z, Almeida C and Zhao W: ERK/ GSK3 $\beta /$ Snail signaling mediates radiation-induced alveolar epithelial-to-mesenchymal transition. Free Radic Biol Med 52: 983-992, 2012

54. Weiss MB, Abel EV, Mayberry MM, Basile KJ, Berger AC and Aplin AE: TWIST1 is an ERK1/2 effector that promotes invasion and regulates MMP-1 expression in human melanoma cells. Cancer Res 72: 6382-6392, 2012.

55. Fu XT, Dai Z, Song K, Zhang ZJ, Zhou ZJ, Zhou SL, Zhao YM, Xiao YS, Sun QM, Ding ZB, et al: Macrophage-secreted IL-8 induces epithelial-mesenchymal transition in hepatocellular carcinoma cells by activating the JAK2/STAT3/Snail pathway. Int J Oncol 46: 587-596, 2015.

56. Fernando RI, Castillo MD, Litzinger M, Hamilton DH and Palena C: IL-8 signaling plays a critical role in the epithelialmesenchymal transition of human carcinoma cells. Cancer Res 71: 5296-5306, 2011.

57. Techasen A, Loilome W, Namwat N, Dokduang H, Jongthawin J and Yongvanit P: Cytokines released from activated human macrophages induce epithelial mesenchymal transition markers of cholangiocarcinoma cells. Asian Pac J Cancer Prev 13 (Suppl): S115-S118, 2012

58. Katsuno Y, Lamouille S and Derynck R: TGF- $\beta$ signaling and epithelial-mesenchymal transition in cancer progression. Curr Opin Oncol 25: 76-84, 2013.

59. Zhang H, Liu L, Wang Y, Zhao G, Xie R, Liu C, Xiao X, Wu K, Nie Y, Zhang H, et al: KLF8 involves in TGF-beta-induced EMT and promotes invasion and migration in gastric cancer cells. J Cancer Res Clin Oncol 139: 1033-1042, 2013

60. Wendt MK, Allington TM and Schiemann WP: Mechanisms of the epithelial-mesenchymal transition by TGF-beta. Future Oncol 5: 1145-1168, 2009.

61. Peinado H, Olmeda D and Cano A: Snail, Zeb and bHLH factors in tumour progression: An alliance against the epithelial phenotype? Nat Rev Cancer 7: 415-428, 2007.

62. Bonde AK, Tischler V, Kumar S, Soltermann A and Schwendener RA: Intratumoral macrophages contribute to epithelial-mesenchymal transition in solid tumors. BMC Cancer 12: 35, 2012

63. Yu Y, Xiao CH, Tan LD, Wang QS, Li XQ and Feng YM: Cancerassociated fibroblasts induce epithelial-mesenchymal transition of breast cancer cells through paracrine TGF- $\beta$ signalling. Br J Cancer 110: 724-732, 2014.
64. Henson ES and Gibson SB: Surviving cell death through epidermal growth factor (EGF) signal transduction pathways: Implications for cancer therapy. Cell Signal 18: 2089-2097, 2006.

65. Barr S, Thomson S, Buck E, Russo S, Petti F, Sujka-Kwok I, Eyzaguirre A, Rosenfeld-Franklin M, Gibson NW, Miglarese M, et al: Bypassing cellular EGF receptor dependence through epithelial-to-mesenchymal-like transitions. Clin Exp Metastasis 25: 685-693, 2008.

66. Clapéron A, Mergey M, Nguyen Ho-Bouldoires TH, Vignjevic D, Wendum D, Chrétien Y, Merabtene F, Frazao A, Paradis V, Housset $\mathrm{C}$, et al: EGF/EGFR axis contributes to the progression of cholangiocarcinoma through the induction of an epithelialmesenchymal transition. J Hepatol 61: 325-332, 2014.

67. Sullivan NJ, Sasser AK, Axel AE, Vesuna F, Raman V, Ramirez N, Oberyszyn TM and Hall BM: Interleukin-6 induces an epithelial-mesenchymal transition phenotype in human breast cancer cells. Oncogene 28: 2940-2947, 2009.

68. Rojas A, Liu G, Coleman I, Nelson PS, Zhang M, Dash R, Fisher PB, Plymate SR and Wu JD: IL-6 promotes prostate tumorigenesis and progression through autocrine cross-activation of IGF-IR. Oncogene 30: 2345-2355, 2011.

69. Xiong H, Hong J, Du W, Lin YW, Ren LL, Wang YC, Su WY, Wang JL, Cui Y, Wang ZH, et al: Roles of STAT3 and ZEB1 proteins in E-cadherin down-regulation and human colorectal cancer epithelial-mesenchymal transition. J Biol Chem 287: 5819-5832, 2012.

70. Liu RY, Zeng Y, Lei Z, Wang L, Yang H, Liu Z, Zhao J and Zhang HT: JAK/STAT3 signaling is required for TGF- $\beta$-induced epithelial-mesenchymal transition in lung cancer cells. Int J Oncol 44: 1643-1651, 2014.

71. Shih JY and Yang PC: The EMT regulator slug and lung carcinogenesis. Carcinogenesis 32: 1299-1304, 2011.

72. Dohadwala M, Wang G, Heinrich E, Luo J, Lau O, Shih H, Munaim Q, Lee G, Hong L and Lai C: The role of ZEB1 in the inflammation-induced promotion of EMT in HNSCC. Otolaryngol Head Neck Surg 142: 753-759, 2010.

73. St John MA, Dohadwala M, Luo J, Wang G, Lee G, Shih H, Heinrich E, Krysan K, Walser T, Hazra S, et al: Proinflammatory mediators upregulate snail in head and neck squamous cell carcinoma. Clin Cancer Res 15: 6018-6027, 2009.

74. Petrella BL, Armstrong DA and Vincenti MP: Interleukin-1 beta and transforming growth factor-beta 3 cooperate to activate matrix metalloproteinase expression and invasiveness in A549 lung adenocarcinoma cells. Cancer Lett 325: 220-226, 2012.

75. Balkwill F: Tumour necrosis factor and cancer. Nat Rev Cancer 9: 361-371, 2009

76. Wu ST, Sun GH, Hsu CY, Huang CS, Wu YH, Wang HH and Sun KH: Tumor necrosis factor- $\alpha$ induces epithelial-mesenchymal transition of renal cell carcinoma cells via a nuclear factor kappa B-independent mechanism. Exp Biol Med (Maywood) 236: 1022-1029, 2011.

77. Schraufstatter IU, Zhao M, Khaldoyanidi SK and Discipio RG: The chemokine CCL18 causes maturation of cultured monocytes to macrophages in the M2 spectrum. Immunology 135: 287-298, 2012.

78. Chen P, Li K, Liang Y, Li L and Zhu X: High NUAK1 expression correlates with poor prognosis and involved in NSCLC cells migration and invasion. Exp Lung Res 39: 9-17, 2013.

79. Zhang B, Yin C, Li H, Shi L, Liu N, Sun Y, Lu S, Liu Y, Sun L, Li X, et al: Nirl promotes invasion of breast cancer cells by binding to chemokine (C-C motif) ligand 18 through the $\mathrm{PI} 3 \mathrm{~K} / \mathrm{Akt} / \mathrm{GSK} 3 \beta /$ Snail signalling pathway. Eur J Cancer 49: 3900-3913, 2013.

80. Grosse-Steffen T, Giese T, Giese N, Longerich T, Schirmacher P, Hänsch GM and Gaida MM: Epithelial-to-mesenchymal transition in pancreatic ductal adenocarcinoma and pancreatic tumor cell lines: The role of neutrophils and neutrophil-derived elastase. Clin Dev Immunol 2012: 720768, 2012.

81. Inoue K, Slaton JW, Eve BY, Kim SJ, Perrotte P, Balbay MD, Yano S, Bar-Eli M, Radinsky R, Pettaway CA, et al: Interleukin 8 expression regulates tumorigenicity and metastases in androgenindependent prostate cancer. Clin Cancer Res 6: 2104-2119, 2000.

82. Kitadai Y, Haruma K, Mukaida N, Ohmoto Y, Matsutani N, Yasui W, Yamamoto S, Sumii K, Kajiyama G, Fidler IJ, et al: Regulation of disease-progression genes in human gastric carcinoma cells by interleukin 8. Clin Cancer Res 6: 2735-2740, 2000 . 
83. Jamieson T, Clarke M, Steele CW, Samuel MS, Neumann J, Jung A, Huels D, Olson MF, Das S, Nibbs RJ, et al: Inhibition of CXCR2 profoundly suppresses inflammation-driven and spontaneous tumorigenesis. J Clin Invest 122: 3127-3144, 2012.

84. Lee YS, Choi I, Ning Y, Kim NY, Khatchadourian V, Yang D, Chung HK, Choi D, LaBonte MJ, Ladner RD, et al: Interleukin-8 and its receptor CXCR2 in the tumour microenvironment promote colon cancer growth, progression and metastasis. $\mathrm{Br} \mathrm{J}$ Cancer 106: 1833-1841, 2012.

85. Yang G, Rosen DG, Liu G, Yang F, Guo X, Xiao X, Xue F, Mercado-Uribe I, Huang J, Lin SH, et al: CXCR2 promotes ovarian cancer growth through dysregulated cell cycle, diminished apoptosis, and enhanced angiogenesis. Clin Cancer Res 16: 3875-3886, 2010.

86. Tazzyman S, Barry ST, Ashton S, Wood P, Blakey D, Lewis CE and Murdoch C: Inhibition of neutrophil infiltration into A549 lung tumors in vitro and in vivo using a CXCR2-specific antagonist is associated with reduced tumor growth. Int J Cancer 129 847-858, 2011.
87. Singh JK, Farnie G, Bundred NJ, Simões BM, Shergill A, Landberg G, Howell SJ and Clarke RB: Targeting CXCR1/2 significantly reduces breast cancer stem cell activity and increases the efficacy of inhibiting HER2 via HER2-dependent and -independent mechanisms. Clin Cancer Res 19: 643-656, 2013.

88. Grund EM, Kagan D, Tran CA, Zeitvogel A, Starzinski-Powitz A, Nataraja $S$ and Palmer SS: Tumor necrosis factor-alpha regulates inflammatory and mesenchymal responses via mitogen-activated protein kinase kinase, p38, and nuclear factor kappaB in human endometriotic epithelial cells. Mol Pharmacol 73: 1394-1404, 2008. 